\title{
Influence of anatomical variations on lumbar foraminal stenosis pathogenesis
}

\author{
Sophie Merckaert $\cdot$ Katarzyna Pierzchala \\ Gerit Kulik · Constantin Schizas
}

Received: 22 January 2014/Revised: 17 August 2014/Accepted: 18 August 2014/Published online: 29 August 2014

(C) Springer-Verlag Berlin Heidelberg 2014

\begin{abstract}
Introduction Symptomatic foraminal stenosis has been observed in patients with degenerative disc disease, scoliosis, asymmetrical disc degeneration and spondylolisthesis. Nevertheless not all patients with the above pathologies will develop symptomatic foraminal stenosis. We hypothesised that symptomatic patients have anatomical predisposition to foraminal stenosis, namely a larger pedicle height $(\mathrm{PH})$ to vertebral body height $(\mathrm{VH})$ ratio, leaving less room below the pedicle for the exiting nerve root compared to asymptomatic patients.

Patient sample 66 Patients were divided in two groups. The surgical group consisted of 37 patients (average age of 61 years) who presented with severe radicular symptoms resisting to conservative measures and requiring decompression and transforaminal lumbar interbody fusion (TLIF). The control group consisted of 29 patients (average age of 51 years) presenting with low back pain (LBP) but with no radicular symptoms and who were treated conservatively.

Methods We measured $\mathrm{VH}$ at the level of the posterior wall as well as PH on parasagittal images (CT or MRI) on all lumbar levels (L1 to L5). Statistical analysis was performed using Student's $t$ test.
\end{abstract}

S. Merckaert · K. Pierzchala $\cdot$ G. Kulik $\cdot$ C. Schizas $(\square)$ Orthopedic Department, Centre Hospitalier Universitaire Vaudois (CHUV) and University of Lausanne,

1011 Lausanne, Switzerland

e-mail: cschizas@hotmail.com

S. Merckaert

e-mail: sophie@merckaert.ch

K. Pierzchala

e-mail: pierzchala.katarzyna@gmail.com

C. Schizas

Neuro-Orthopaedic Spine Unit, Clinique Cecil, Lausanne, Switzerland
Results No difference in PH was found between the two groups for L1 to L4 levels. By contrast, there was a highly statistically significant difference in VH between the two groups from L1 to L4 level. In the surgical group, the $\mathrm{VH}$ was smaller $(p<0.001)$.

Conclusions Symptomatic patients with foraminal stenosis have smaller VH leading to lesser space beneath the pedicle and putting the exiting nerve root at risk in cases of spondylolisthesis or disc degeneration.

Keywords Foraminal stenosis - Spondylolisthesis . Degenerative disc disease $\cdot$ Scoliosis

\section{Introduction}

Degenerative disc disease, scoliosis with asymmetrical disc degeneration and spondylolisthesis can lead to foraminal stenosis. Nevertheless not all patients with the above disease will develop radiological stenosis or symptoms [1].

Several authors reported on the morphology of the lumbar vertebral foramen [2-5] but to our knowledge the relationship between vertebral height and pedicle height has not been studied.

We hypothesised that patients who develop symptomatic foraminal stenosis in the presence of the above-mentioned pathologies have an anatomical predisposition namely a different pedicle height $(\mathrm{PH})$ to vertebral height (VH) relationship compared to asymptomatic subjects.

\section{Materials and methods}

A total of 66 patients were studied. Thirty-seven consecutive surgically treated patients (all undergoing 
transforaminal lumbar interbody fusion (TLIF) performed by a single surgeon) with symptomatic lumbar foraminal stenosis with pain of radicular origin were included (surgical group). From those, 19 patients presented with symptomatic foraminal stenosis secondary to degenerative scoliosis (8 cases) or asymmetrical disc degeneration (11 cases) whilst in 18 patients it was secondary to grade I isthmic spondylolisthesis. Radicular symptoms were unilateral in 34 patients (23 left sided and 11 right sided) and bilateral in three. Patients undergoing TLIF procedure with radicular symptoms not solely related to foraminal stenosis but also due to lateral recess stenosis were excluded from this study. The control group consisted of 29 conservatively treated low back pain (LBP) patients none of whom presented with radicular symptoms (LBP group). Average age was of 61 (SD 12) years for the surgical group and 51 (SD16) years in the LBP group. Male to female ratio was 0.8 in both groups. Radiological measurements were performed by two independent observers on T1/T2 MRI weighted images on 52 subjects. The remaining 14 patients had measurements on CT due to unavailability of MRI images on the institutional PACS system given the reported excellent measurement correlation between the abovementioned imaging techniques [6]. All measurements were performed using the Osirix image processing software.

We measured vertebral body height $(\mathrm{VH})$ and pedicular height $(\mathrm{PH})$ on left and right sides on all lumbar levels from L1 to L5 in a standardised manner: VH was measured on parasagittal images along a line perpendicular to the inferior end plate and at the level of the posterior wall. $\mathrm{PH}$ was measured at the middle of the pedicle and perpendicular to its long axis (Fig. 1).

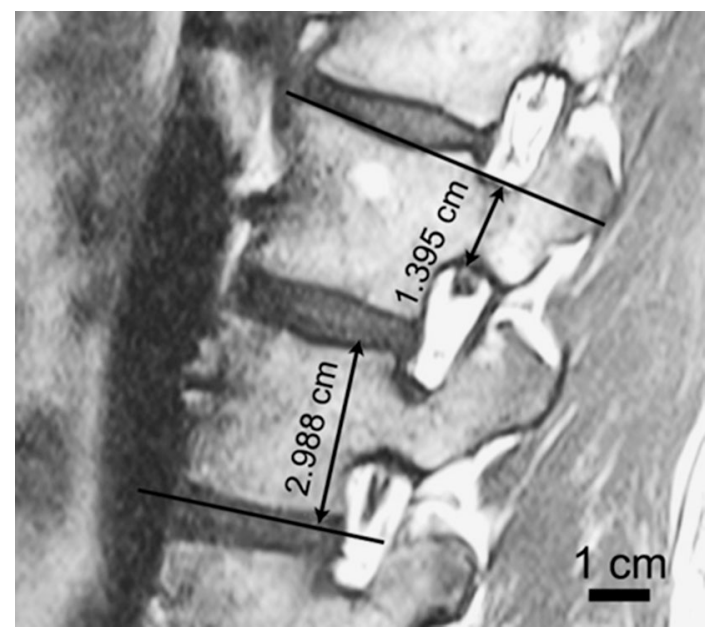

Fig. 1 Sagittal T1-weighted MRI image showing measuring technique. VH was measured on parasagittal images along a line perpendicular to the inferior end plate and at the level of the posterior wall. PH was measured at the middle of the pedicle and perpendicular to its long axis
Data was analysed per vertebral level as well as per gender. Also, analysis was performed comparing results according to laterality (left with left and right with right side for both groups) as well as based on the side of the radicular symptoms. Statistical analysis was performed using student's $t$ test.

\section{Results}

Intra- and interobserver reliability of measurements was almost perfect (ICC of 0.983 and 0.975 , respectively). Numerical values per level for $\mathrm{VH}$ and $\mathrm{PH}$ are given in Table 1 and 2 .

On analysing the data for both genders and both groups combined, we found that $\mathrm{VH}$ increased from L1 to L4 whilst it was the smallest at L5. In contrast, PH decreased in cranio-caudal direction from L1 to L5 in both surgical and conservative groups.

The main finding was that overall there was a statistically significant difference in VH between the two groups, the control group having higher vertebral bodies at all lumbar levels. By contrast, PH was similar in both groups.

When analysing data according to gender, we found that males had bigger $\mathrm{VH}$ and $\mathrm{PH}$ than women except at L5 level in the surgical group.

A detailed comparison between groups is displayed in Table 3.

While analysing the $\mathrm{PH} / \mathrm{VH}$ ratio, we found that it was higher in surgical group for L1 to L3 $(p<0.05)$ considering both genders. In L4 and L5, we observed no ratio difference.

Histogram of $\mathrm{PH} / \mathrm{VH}$ ratio of L3 for both groups (the level where the $p$ value was the smallest $(p<0.001)$ can be seen in Fig. 2.

Dichotomising the data around a $\mathrm{PH} / \mathrm{VH}$ ratio $>0.525$ allows defining an odds ratio (OR) of five as far as the need of surgery is concerned. Patients with ratios in this range have, therefore, at least a fivefold chance to have anatomical predisposition towards a symptomatic foraminal stenosis.

\section{Discussion}

The main finding of our study was that patients with symptomatic foraminal stenosis have smaller VH but same $\mathrm{PH}$ compared to controls. This results in less space below the pedicle, leaving the nerve root vulnerable to compression in case of asymmetrical disc degeneration or spondylolisthesis as illustrated (Fig. 3). Patients, whose pedicle is higher than half a vertebral body, have a fivefold risk to be symptomatic. 
Table 1 Comparative radiological measurement of posterior $\mathrm{VH}$ (mean \pm standard deviation)

\begin{tabular}{lllllll}
\hline $\begin{array}{l}\text { Total } \\
\left(n_{S}=37,\right. \\
\left.n_{C}=29\right)\end{array}$ & Control R [mm] & $\begin{array}{l}\text { Surgical R } \\
{[\mathrm{mm}]}\end{array}$ & $p$ value & Control L [mm] & $\begin{array}{l}\text { Surgical L } \\
{[\mathrm{mm}]}\end{array}$ & $p$ value \\
\hline $\mathrm{L}_{1} \mathrm{VH}$ & $27.093 \pm 2.556$ & $25.960 \pm 1.729$ & 0.036 & $27.531 \pm 2.305$ & $26.181 \pm 1.592$ & 0.007 \\
$\mathrm{~L}_{2} \mathrm{VH}$ & $27.739 \pm 2.131$ & $26.045 \pm 1.795$ & 0.001 & $28.494 \pm 2.266$ & $26.446 \pm 1.828$ & 0.000 \\
$\mathrm{~L}_{3} \mathrm{VH}$ & $28.086 \pm 2.153$ & $26.780 \pm 1.484$ & 0.005 & $27.969 \pm 2.283$ & $26.696 \pm 1.834$ & 0.053 \\
$\mathrm{~L}_{4} \mathrm{VH}$ & $28.135 \pm 1.887$ & $26.916 \pm 2.082$ & 0.016 & $28.585 \pm 2.031$ & $27.399 \pm 2.498$ & 0.042 \\
$\mathrm{~L}_{5} \mathrm{VH}$ & $25.584 \pm 2.053$ & $23.682 \pm 2.477$ & 0.001 & $25.520 \pm 2.194$ & $23.076 \pm 2.023$ & 0.000 \\
\hline
\end{tabular}

Table 2 Comparative radiological measurement of $\mathrm{PH}$ (mean \pm standard deviation)

\begin{tabular}{lllllll}
\hline $\begin{array}{l}\text { Total } \\
\left(n_{S}=37,\right. \\
\left.n_{C}=29\right)\end{array}$ & Control R [mm] & $\begin{array}{l}\text { Surgical R } \\
{[\mathrm{mm}]}\end{array}$ & $p$ value & Control L $[\mathrm{mm}]$ & $\begin{array}{l}\text { Surgical L } \\
{[\mathrm{mm}]}\end{array}$ & $p$ value \\
\hline $\mathrm{L}_{1} \mathrm{PH}$ & $13.278 \pm 1.538$ & $13.586 \pm 1.427$ & 0.403 & $13.468 \pm 1.646$ & $13.245 \pm 1.449$ & 0.562 \\
$\mathrm{~L}_{2} \mathrm{PH}$ & $12.581 \pm 1.573$ & $12.812 \pm 1.558$ & 0.554 & $13.200 \pm 1.862$ & $12.723 \pm 1.426$ & 0.242 \\
$\mathrm{~L}_{3} \mathrm{PH}$ & $12.364 \pm 1.307$ & $12.372 \pm 1.479$ & 0.983 & $12.270 \pm 1.133$ & $12.546 \pm 1.475$ & 0.409 \\
$\mathrm{~L}_{4} \mathrm{PH}$ & $11.940 \pm 1.578$ & $11.681 \pm 1.569$ & 0.508 & $11.845 \pm 1.549$ & $11.824 \pm 1.608$ & 0.960 \\
$\mathrm{~L}_{5} \mathrm{PH}$ & $11.346 \pm 1.674$ & $10.826 \pm 1.692$ & 0.217 & $11.157 \pm 1.553$ & $10.695 \pm 1.542$ & 0.050 \\
\hline
\end{tabular}

Table 3 Detailed comparison between groups

\begin{tabular}{|c|c|c|c|c|c|c|}
\hline & & $\begin{array}{l}\text { Whole group } \\
\text { conservative vs. } \\
\text { surgical }\end{array}$ & $\begin{array}{l}\text { Male control (MC) vs. } \\
\text { female control (FC) }\end{array}$ & $\begin{array}{l}\text { Male surgical(MS) vs. } \\
\text { female surgical(FS) }\end{array}$ & $\begin{array}{l}\text { Male control (MC) vs. } \\
\text { male surgical (MS) }\end{array}$ & $\begin{array}{l}\text { Female control (FC) vs. } \\
\text { female surgical (FS) }\end{array}$ \\
\hline \multirow[t]{2}{*}{ L1 } & VH & $\mathrm{C}>\mathrm{S}^{*}$ & $\mathrm{MC}>\mathrm{FC}(\mathrm{ns})$ & $\mathrm{MS}>\mathrm{FS}^{*}$ & $\mathrm{MC}>\mathrm{MS}(\mathrm{ns})$ & $\mathrm{FC}>\mathrm{FS} *($ left only $)$ \\
\hline & PH & $\mathrm{C}=\mathrm{S}$ & $\mathrm{MC}>\mathrm{FC}^{*}$ & $\mathrm{MS}>\mathrm{FS}^{*}$ & $\mathrm{MC}=\mathrm{MS}$ & $\mathrm{FC}=\mathrm{FS}$ \\
\hline \multirow[t]{2}{*}{ L2 } & VH & $\mathrm{C}>\mathrm{S}^{* *}$ & $\mathrm{MC}>\mathrm{FC}(\mathrm{ns})$ & $\mathrm{MS}>\mathrm{FS}^{*}$ & $\mathrm{MC}>\mathrm{MS}(\mathrm{ns})$ & $\mathrm{FC}>\mathrm{FS}^{*}$ \\
\hline & PH & $\mathrm{C}=\mathrm{S}$ & MC $>$ FC*(left side $)$ & MS > FS (ns) & $\mathrm{MC}=\mathrm{MS}$ & $\mathrm{FC}=\mathrm{FS}$ \\
\hline \multirow[t]{2}{*}{ L3 } & VH & $\mathrm{C}>\mathrm{S}^{*}$ & $\mathrm{MC}>\mathrm{FC}(\mathrm{ns})$ & MS $>$ FS*(right side $)$ & $\mathrm{MC}>\mathrm{MS}(\mathrm{ns})$ & $\mathrm{FC}>\mathrm{FS}^{*}$ \\
\hline & $\mathrm{PH}$ & $\mathrm{C}=\mathrm{S}$ & $\mathrm{MC}>\mathrm{FC}(\mathrm{ns})$ & MS $>$ FS*(left side $)$ & $\mathrm{MC}=\mathrm{MS}$ & $\mathrm{FC}=\mathrm{FS}$ \\
\hline \multirow[t]{2}{*}{ L4 } & VH & $\mathrm{C}>\mathrm{S}^{*}$ & $\mathrm{MC}>\mathrm{FC}(\mathrm{ns})$ & $\mathrm{MS}>\mathrm{FS}^{*}$ & $\mathrm{MC}=\mathrm{MS}$ & $\mathrm{FC}>\mathrm{FS}^{*}$ \\
\hline & $\mathrm{PH}$ & $\mathrm{C}=\mathrm{S}$ & MC $>$ FC*(left side) & $\mathrm{MS}=\mathrm{FS}$ & $\mathrm{MC}=\mathrm{MS}$ & $\mathrm{FC}=\mathrm{FS}$ \\
\hline \multirow[t]{2}{*}{ L5 } & $\mathrm{VH}$ & $\mathrm{C}>\mathrm{S}^{* *}$ & $\mathrm{MC}>\mathrm{FC}(\mathrm{ns})$ & $\mathrm{MS}=\mathrm{FS}$ & $\mathrm{MC}>\mathrm{MS}^{*}$ & $\mathrm{FC}>\mathrm{FS}^{*}$ \\
\hline & PH & $\mathrm{C}=\mathrm{S}$ & $\mathrm{MC}>\mathrm{FC}^{*}$ & $\mathrm{MS}=\mathrm{FS}$ & $\mathrm{MC}>\mathrm{MS}^{*}$ & $\mathrm{FC}=\mathrm{FS}$ \\
\hline
\end{tabular}

$* p<0.05, * * p<0.001, n s-$ non-significant

Even though absolute numerical values appear small they correspond to a pedicle occupying from less than a third of the pedicle height to more than half the vertebral height, which is clinically relevant.

The difference in anatomy applies not only to the symptomatic level and side but also to the unaffected levels as illustrated in Fig. 4.

This suggests that the differences observed are not a consequence of secondary changes such as VH loss at the symptomatic side in patients with asymmetrical degeneration or scoliosis.

Patients of the surgical group were on average 10 years older than those of the control group. Given that there was a greater proportion of women in both groups one could hypothesise that osteoporosis (not documented in our series for all patients) could have played a role. Indeed, Gilsanz et al. [7] found that women with osteoporosis (regardless weather they had a fracture or not) had smaller vertebral bodies. In contrast, Ferrar and et al. [8] found that short VH without end plate fracture was present in younger women without osteoporosis as well as in older ones with osteoporosis and, therefore, was not associated to low bone density.

Several papers looked at pathogenesis of foraminal stenosis and foraminal anatomy.

Research was performed on cadavers with no clinical correlation [9] [5] or focusing on dynamic changes with no inclusion of a control group for comparison [10, 11]. 
To our knowledge, there is no study considering the relationship between $\mathrm{PH}$ and $\mathrm{VH}$.

Kaneko published a morphometric analysis comparing foraminal dimensions of degenerative scoliosis subjects with an LBP control group. They found that foraminal area was smaller in the scoliosis group not only on the concave side but also on the convex side. [4] It is possible that this difference in area is secondary to the anatomical differences we noted in our present study.

Even though numerical differences between groups were small in our series (a seen in Table 1 for VH measurements), the fact that there was an excellent intra- and interobserver agreement suggest that our findings are not

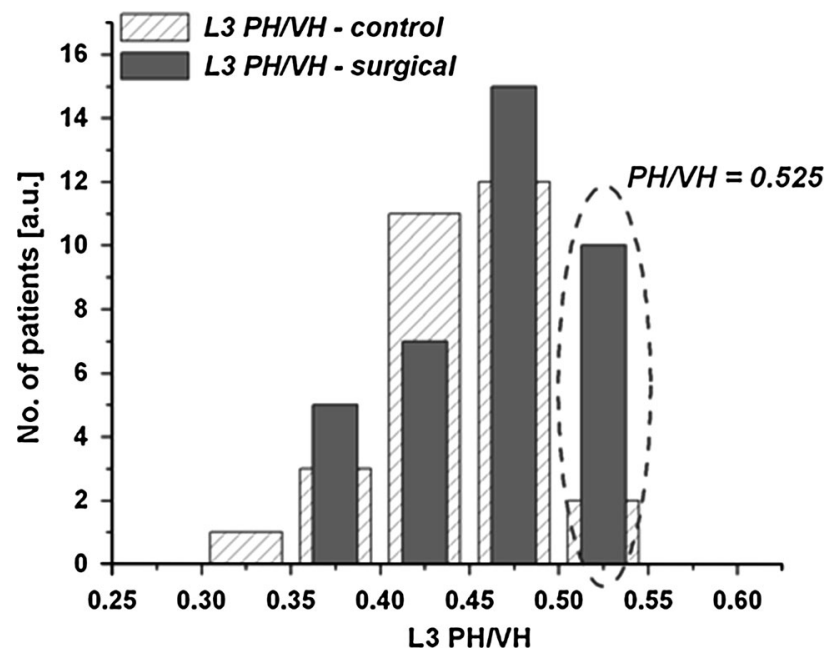

Fig. 2 Histogram of PH/VH ratio of L3 for both groups (the level where the $p$ value was the smallest) due to measurement error but represent a consistent difference between groups.

Even though measurements were performed on both CT and MRIs in our series, previous research suggests that the correlation of measurements between the aforementioned imaging modalities is excellent. [6].

Patients with asymmetrical disc disease or degenerative scoliosis were only included in the surgical group. Since sagittal images would be oblique in some cases, this would result in apparent lengthening of both the pedicle and vertebral height in the same proportion. More importantly in the surgical group, those patients would have even bigger $\mathrm{VH}$ values than measured. The true $\mathrm{VH}$ in this proportion of surgical patients is, therefore, even smaller than the one measured, further strengthening our hypothesis.

Our control group did not consist of patients with spondylolisthesis or degenerative scoliosis who were asymptomatic. We feel nevertheless that this comparison would be less valid since a number of those asymptomatic patients might have an anatomical predisposing factor and only become symptomatic later in life. This is reflected also by significant differences in the reported incidence of symptomatic foraminal stenosis in degenerative scoliosis patients ranging from $13 \%$ [1] to $100 \%$ [12].

Our imaging studies were performed in a supine position. We only studied bony anatomy and therefore weight bearing would not affect the results unlike in studies looking at foraminal dimensions as a whole. Indeed Fujiwara et al. [13] showed that foraminal anatomy changes with flexion, extension, lateral bending and rotations and therefore have a contribution to development of radicular pain.
Fig. 3 Effect of observed anatomical differences on foraminal dimensions and root entrapment exaggerated for illustrative purposes. a Top row asymptomatic subjects.

b Bottom row symptomatic subjects. $V H$ vertebral height, $P H$ pedicle height, $N R$ nerve root, $D H$ disc height. On the far right, MRI examples of asymptomatic (top) and symptomatic (bottom) patient (a)
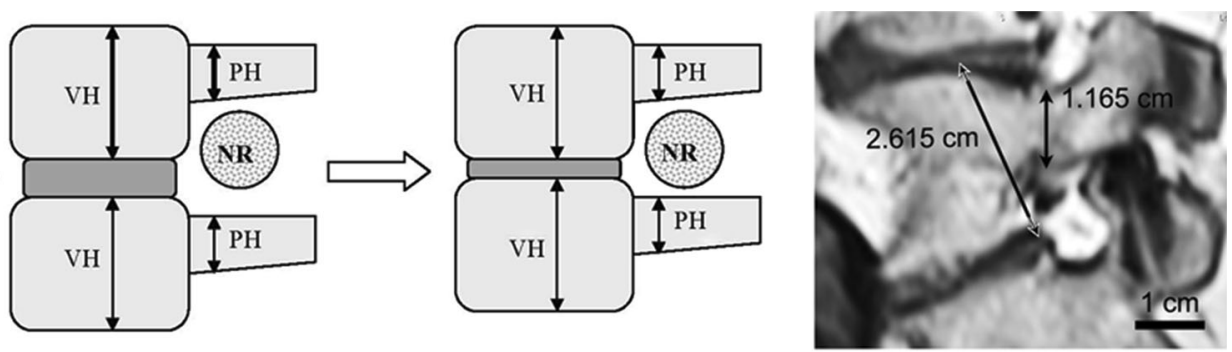

(b)
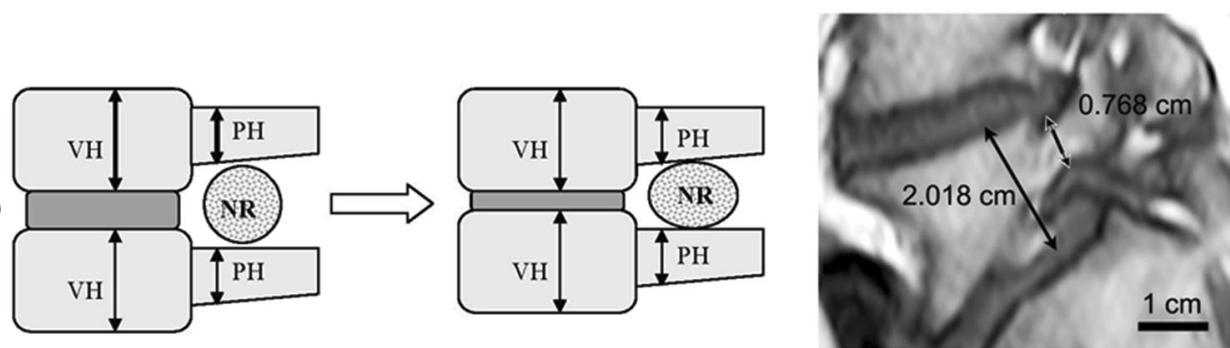


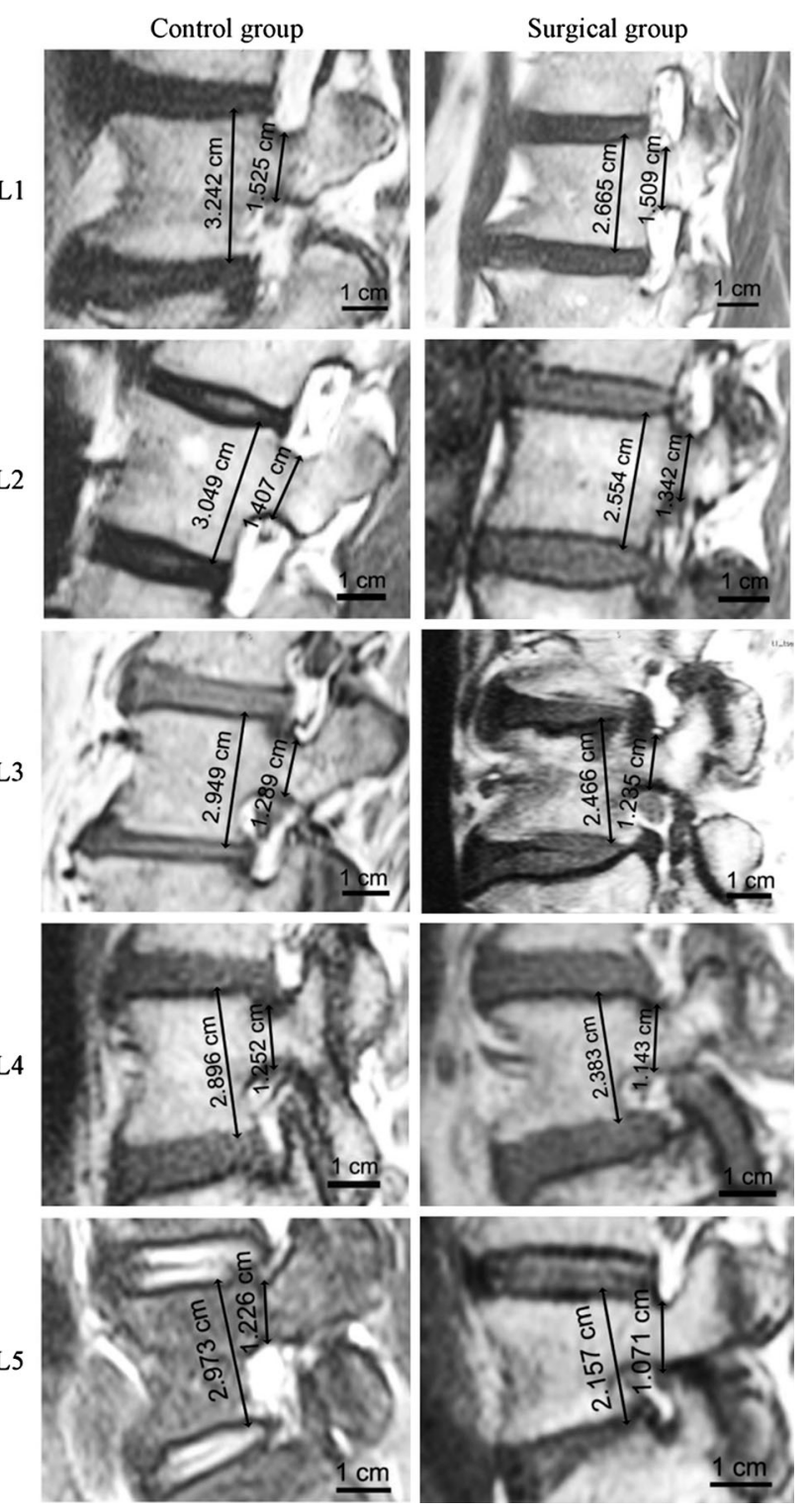

Fig. 4 Parasagittal MRI images showing the extreme dimension values for both groups

As we only looked at bony parameters and not on the neural tissue anatomy, one could argue that symptomatic stenosis is more in relation to discrepancy between the foraminal and neural dimensions as this has been suggested in lumbar spinal stenosis [14].

Our findings might assist clinicians in deciding if prophylactic stabilisation is warranted at the level of asymmetrical disc degeneration should decompressive surgery be performed for central canal stenosis at that level. The senior author routinely performs TLIF procedures if there is concomitant central and foraminal stenosis with significant asymmetrical disc degeneration but to our knowledge there are no randomised trials supporting this practice. We have recently implemented the above findings in clinical practice and started measuring the $\mathrm{PH} / \mathrm{VH}$ ratio. If this ratio is bigger than 0.5 , i.e. if the pedicle occupies more than half of the vertebral body, we would seriously consider stabilising this segment if we were to perform a decompressive procedure for central stenosis. This is based on our anecdotal experience of secondary symptomatic foraminal stenosis in cases of asymmetrical disc degeneration undergoing decompression without fusion. Further research in this subject would be of great interest.

Patients with symptomatic foraminal stenosis have significant anatomical differences in vertebral height when compared with non-symptomatic patients. This difference results in a diminished distance below the pedicle, leaving the nerve root vulnerable to compression in case of disc degeneration or spondylolisthesis.

\section{References}

1. Simmons EH, Jackson RP (1979) The management of nerve root entrapment syndromes associated with the collapsing scoliosis of idiopathic lumbar and thoracolumbar curves. Spine 4:533-541

2. Hasegawa T, An HS, Haughton VM, Nowicki BH (1995) Lumbar foraminal stenosis: critical heights of the intervertebral discs and foramina. A cryomicrotome study in cadavera. J Bone Joint Surg Am 77:32-38

3. Torun F, Dolgun H, Tuna H, Attar A, Uz A, Erdem A (2006) Morphometric analysis of the roots and neural foramina of the lumbar vertebrae. Surgical neurology 66:148-151. doi:10.1016/j. surneu.2006.02.041 (Discussion 151)

4. Kaneko Y, Matsumoto M, Takaishi H, Nishiwaki Y, Momoshima S, Toyama Y (2012) Morphometric analysis of the lumbar intervertebral foramen in patients with degenerative lumbar scoliosis by multidetector-row computed tomography. Eur Spine J 21:2594-2602. doi:10.1007/s00586-012-2408-7

5. Cinotti G, De Santis P, Nofroni I, Postacchini F (2002) Stenosis of lumbar intervertebral foramen: anatomic study on predisposing factors. Spine 27:223-229

6. Schulte TL, Heidenreich JO, Schilling AM, Stendel R, Pietila TA, Hopfenmuller W, Brock M, Wolf KJ (2004) Comparison of metric analysis of spinal structures, exemplarily of the ligamentum flavum, obtained with $\mathrm{CT}$ and MRI. Eur J Radiol 52:224-228. doi:10.1016/j.ejrad.2003.11.022

7. Gilsanz V, Loro ML, Roe TF, Sayre J, Gilsanz R, Schulz EE (1995) Vertebral size in elderly women with osteoporosis. Mechanical implications and relationship to fractures. J Clin Investig 95:2332-2337. doi:10.1172/JCI117925

8. Ferrar L, Roux C, Reid DM, Felsenberg D, Gluer CC, Eastell R (2012) Prevalence of non-fracture short vertebral height is similar in premenopausal and postmenopausal women: the osteoporosis and ultrasound study. Osteoporos Int 23:1035-1040. doi:10.1007/ s00198-011-1657-3

9. Torun F, Tuna H, Buyukmumcu M, Caglar S, Baysefer A (2008) The lumbar roots and pedicles: a morphometric analysis and anatomical features. J Clin Neurosci 15:895-899. doi:10.1016/j. jocn.2007.08.006

10. Jenis LG, An HS (2000) Spine update. Lumbar foraminal stenosis. Spine 25:389-394

11. Nowicki BH, Haughton VM, Schmidt TA, Lim TH, An HS, Riley LH 3rd, Yu L, Hong JW (1996) Occult lumbar lateral spinal 
stenosis in neural foramina subjected to physiologic loading. AJNR Am J Neuroradiol 17:1605-1614

12. Fu KM, Rhagavan P, Shaffrey CI, Chernavvsky DR, Smith JS (2011) Prevalence, severity, and impact of foraminal and canal stenosis among adults with degenerative scoliosis. Neurosurgery 69:1181-1187. doi:10.1227/NEU.0b013e31822a9aeb

13. Fujiwara A, An HS, Lim TH, Haughton VM (2001) Morphologic changes in the lumbar intervertebral foramen due to flexion- extension, lateral bending, and axial rotation: an in vitro anatomic and biomechanical study. Spine 26:876-882

14. Schizas C, Theumann N, Burn A, Tansey R, Wardlaw D, Smith FW, Kulik G (2010) Qualitative grading of severity of lumbar spinal stenosis based on the morphology of the dural sac on magnetic resonance images. Spine 35:1919-1924. doi:10.1097/ BRS.0b013e3181d359bd 